\title{
A ANÁLISE DO DISCURSO EM EMPREENDEDORISMO SOCIAL: O CASO DA REDE IVG - BRASIL
}

\author{
Monica Cristina Rovaris Machado ${ }^{1}$, Fernando César Lenzi ${ }^{2}$ e Clemente Antonio Penalva \\ Verdú ${ }^{3}$ \\ ${ }^{1}$ Universidade Federal de Sergipe - UFS- Brasil, monicarovarisdoutorado@gmail.com \\ ${ }^{2}$ Universidade do Vale do Itajai - Univali , Brasil, lenzi@univali.br \\ ${ }^{3}$ Universidade de Alicante - UA - España, clemente.penalva@ua.es
}

\begin{abstract}
Resumo. O artigo tem como objetivo identificar os valores sob a ótica dos sujeitos de uma rede de organizações sociais, chamada Rede IVG. Os valores levantados juntos aos sujeitos tiveram como base a Teoria de Valores de Schwartz (2012) e a Teoria de Valores Culturais de Inglehart (1977, 1990, 1997), a partir da análise dos seus discursos. A metodologia utilizada foi do tipo exploratório, qualitativa, técnicas de análise orientadas para a construção conceitual a partir de dados não estruturados chamada de Grounded Theory, análise documental e observação não participante, por meio de procedimentos de indução analítica. A análise das informações qualitativas teve como apoio a análise do discurso dos sujeitos e apoio do software Atlas TI para definição dos valores pessoais. Conclui-se que os sujeitos são afetados pelas condições socioeconômicas que influenciam seus valores, pois a sobrevivência é fator determinante afetados pelos fatores sociais, econômicos e políticos, sendo seus valores caracterizados como materialistas, pois necessitam de apoio para a transformação social da comunidade.
\end{abstract}

Palavras-chave: Empreendedorismo Social; Valores; Análise do Discurso; Brasil.

THE DISCOURSE ANALYSIS IN SOCIAL ENTREPRENEURSHIP: THE CASE OF REDE IVG BRAZIL

Abstract: The article has as objective detects the values under the optics of the subjects of a net of social organizations, called Net IVG. The gathered data together to the subjects took as a base Schwartz's valuable Theory (2012) and the Theory of Cultural Values of Inglehart (1977, 1990, 1997), from the analysis of his speeches. The used methodology was of the exploratory study, qualitative, techniques of analysis orientated for the conceptual construction from data not structured when was called Grounded Theory, documentary analysis and observation not participant, through proceedings of analytical induction. The analysis of the qualitative information held as a support the analysis of the speech of the subjects and support of the software Atlas IT for definition of the personal values. It concludes that the subjects are affected by the socioeconomic conditions that influence theirs values. So the survival is a determinative factor when they were affected by the social, economic and political factors, being theirs values characterized like materialists, because they need support for the social transformation of the community.

Keywords: Social Entrepreneurship; Values; Discourse Analysis; Brazil.

\section{INTRODUÇÃO}

A sociedade contemporânea é caracterizada por situações de difíceis soluções, principalmente para os problemas econômicos e sociais, seja para os governos e para as sociedades ou ainda incapacidade na sua resolução, a falta de adequação das instituições governamentais, ou pela falta de recursos (Parente, Costa, Santos, \& Chaves, 2011), e a pobreza e a desigualdade continuam a ser dificuldades enfrentadas pelos países em desenvolvimento (Desai, 2014). 
Entretanto há fatores que contribuem para a resolução destes problemas, principalmente em âmbito local, como por exemplo, formas de trocar e interagir entre as pessoas, bem como a ação de empreendedores com a intenção de simplesmente ajudar os outros (Kostetska \& Berezyak, 2014; Pless, 2012).

O Empreendedorismo Social (ES) tem despertado crescente interesse na academia, apesar de não ser um fenômeno novo (Chell, 2007), sabe-se relativamente pouco sobre as dinâmicas e processos importantes para o avanço social e econômico por ele proporcionado nas comunidades locais (Martin \& Osberg, 2007). Ele emerge num contexto de crise e desafios sociais, econômicos e ambientais nas sociedades contemporâneas (Parente et al., 2011), e pode ser um mecanismo de trocas sociais para o desenvolvimento econômico sustentável (Kostetska \& Berezyak, 2014), ou ainda responsável pela inovação na resolução de problemas sociais (Omorede, 2014; Parente et al., 2011).

A criação de valor estudada em áreas como engenharia, psicologia e sociologia, e agora também integra gestão, mas gera dificuldades devido a gama de agentes e áreas atendidas, pois a criação de valor refere-se tanto ao significado de valor até o processo de criação de novos valores, que consiste em determinar o conteúdo e questões sobre o que é valor ou é valioso, valorizar o quê e onde reside o valor, destacam a complexidade de entendimento sobre a criação de valor gerada pelos empreendimentos sociais (Lepak, Smith, \& Taylor, 2007). Desse modo, este artigo tem como objetivo identificar os valores sob a ótica dos sujeitos na Rede IVG, tendo como base a Teoria de Valores de Schwartz (2012) e a Teoria de Valores Culturais de Inglehart (1977, 1990, 1997), a partir da análise dos seus discursos.

O presente artigo é composto pela introdução, que apresenta os aspectos norteadores gerais como objetivo, problemática e justificativa.

O capítulo 2 apresenta a fundamentação teórica, tendo como foco o empreendedorismo social e a criação de valor. Já o capítulo 3 apresenta o percurso metodológico utilizado na pesquisa de campo.

O capítulo 4 mostra a análise dos dados e evidências da pesquisa com os sujeitos da Rede IVG. No capítulo 5 são apresentadas as conclusões, sugestões de trabalhos futuros e limitação da pesquisa, seguido pelas referencias utilizadas no artigo. 


\section{FUNDAMENTAÇÃO TEÓRICA}

A ideia de ES emergiu rapidamente na sociedade e o interesse nesta nova forma de organização social mostrou-se crescente e tornou-se um fenômeno global que impactou a sociedade por empregar abordagens inovadoras na resolução de problemas sociais, provenientes tanto do setor privado quanto do sem fins lucrativos (Austin, Stevenson \& WeiSkillern, 2006). Mair e Marti (2006) explicam que o Empreendedorismo Social pode ser estudado como um campo independente de pesquisa. Elas argumentam que difere das outras formas de Empreendedorismo na medida em que dá maior prioridade à criação de valor social, por assegurar desempenho e impacto social. Trata da superação de limites impostos pela escassez de recursos, por meio do reconhecimento e da exploração de novas oportunidades (Peredo \& Mclean, 2006). O ES também pode ser definido como a criação e realização de um empreendimento que pretende promover uma finalidade social específica ou causa, num contexto de mobilização, valores que são desejáveis e importantes em uma sociedade contemporânea. Estes valores podem ser: a liberdade, a igualdade e a tolerância, que são pertinentes para a qualidade da vida humana. Já outros estudiosos consideram o ES como um caminho para a transformação social ao invés de recompensa econômica (Alvord, Brown, \& Letts, 2004; Mai \& Martí, 2006; Murphy \& Coombes, 2009). Há que considerar que a definição do ES tem como foco a missão principal do empreendedor social e a criação de valor social, fornecendo soluções para problemas sociais. O ES é definido por seus "dois constituintes elementos: um foco estratégico privilegiado sobre o impacto social e uma abordagem inovadora para cumprimento da sua missão" (Nicholls, 2006, p. 13), ou ainda como afirmam Bacq e Janssen (2011), que há dois principais elementos que caracterizam uma organização de ES: (1) um objetivo social, ou seja, a criação de valor social; e (2) uma estratégia empreendedora, isto é, a aplicação de conhecimentos e habilidades de negócios baseados no mercado. Agostini (2016) afirma que ES são atividades ou práticas desenvolvidas por organizações do terceiro setor, sozinha ou em parceria entre elas, sem o objetivo de lucro, e com um objetivo social.

No que se refere aos estudos sobre valor e seus conceitos remontam ao início dos estudos da humanidade, por meio de filósofos como Sócrates e Platão, e Aristóteles, que apresentou de forma sistematizada no livro Teoria dos Sentimentos Morais (Smith, 1759). Mais recentemente, na área de psicologia social, Schwartz (1992, 2005, 2012; Schwartz, Cieciuch, Vecchione, Davidov, Fischer, \& Konty, 2012), tem contribuído para o desenvolvimento da teoria de valores, mas no contexto organizacional. 
No instrumento Schwartz Value Survey (SVS), Schwartz estabelece critérios em níveis e de maneira circular, organiza e define os valores em dez grupos, sendo num primeiro nível, a saber: Poder, Realização, Estimulação, Hedonismo, Autodeterminação, Universalismo, Benevolência, Tradição, Conformidade e Segurança (Schwartz, 1992; Schwartz et al., 2012). Num segundo nível, Schwartz determina a relação entre os valores pessoais e os tipos motivacionais dos indivíduos, num propósito de estabelecer as semelhanças e as diferenças entre eles, por meio dos propulsores motivacionais para as ações e comportamentos. A partir destas relações, o autor propõe dimensões bipolares, com base nos valores individuais e seus objetivos, entendidas como: "abertura à mudança" (autodeterminação e estimulação) se contrapõe as de "conservação" (segurança, tradição e conformidade), e a outra são os valores de "autotranscedência" (universalismo e benevolência) que se contrapõe aos de "autopromoção" (poder e realização); hedonismo pode situar-se em abertura à mudança ou autopromoção, o que dependerá da amostra (Schwartz, 1992; Schwartz et al., 2012), são chamados valores do tipo motivacionais de segunda ordem, e na terceira ordem, o autor define que são narrativas de vida autodefinidas (Schwartz, 1992, 2017; Schwartz et al., 2012).

Numa perspectiva sociológica, Inglehart $(1977,1990,1997)$ define que para atender as suas necessidades, os indivíduos associam valores, sejam eles materiais ou imateriais, partindo da Teoria das Motivações de Maslow (1954), porém limitou-se a dicotomia material e pósmaterial. No seu modelo, o questionário World Values Survey (WVS) versão sete está estruturado em 14 subseções temáticas, incluindo a demografia, como segue: valores sociais, atitudes e estereótipos, bem-estar social, capital social, confiança e organização, valores econômicos, corrupção, migração, índice pós-materialista, ciência e tecnologia, valores religiosos, segurança, valores e normas éticas, interesse político e participação política, cultura política e regimes políticos, e demografia (Inglehart, 1977, 1990, 1997; World Values Survey, 2018). Após a aplicação do modelo, o diagnóstico resulta em indicadores que são agrupados conforme as prerrogativas materialista ou pós-materialista, apresentando um resultado dicotômico do país ou países analisados. A perspectiva sociológica de valores de Inglehart mostra que existem mudanças que ocorrem pela transformação na ordem social e econômica das sociedades, e que já atingiram níveis básicos de conforto social; são as chamadas sociedades pós-materialistas.

E, por outro lado, as sociedades que enfrentam problemas de escassez econômica, dando prioridade aos bens materiais, escassez de recursos financeiros e estruturais, as chamadas 
sociedades materialistas; isto faz com os valores em ambas as sociedades provoquem ou não mudanças na hierarquia de valores (World Values Survey, 2017).

O movimento da criação de valor nos empreendimentos sociais combina com o processo de criação de soluções inovadoras por meio da descoberta de oportunidades, mobilização e combinação de recursos escassos, alternativas de fontes de receitas, realinhamento de objetivos e estrutura dos empreendimentos, bem como um relacionamento com os stakeholders (Bernardino, 2013; Parente et al., 2011). Para as sociedades plurais e complexas dos dias de hoje, um conceito unilateral de criação de valor é desafiador, pois o que é novo, bom ou valioso depende da interpretação cultural destes conceitos, não podendo ser feito de forma linear e objetiva (Lautermann, 2013). A perspectiva de que criação de valor social é fundamental para a dinâmica desenvolvida nos empreendimentos, de forma que os atores sociais por um lado trazem as ideias, energia para fazer e competência, construindo novas formas de enfrentar os problemas sociais, e por outro lado, o resultado econômico gerado é o motor para o empreendimento, pois contribui para o resultado importante que é a inovação social, que de maneira singular, consolida o progresso social (Martinez, O'Sullivan, Smith \& Esposito, 2107). Quanto à criação de valor em sociedades materialistas e pós-materialistas, as visões são diferentes sob o ponto de vista econômico e social, pois ambas são influenciadas de forma diferente pelos valores disseminados, e tendo também foco diferente no processo de criação de valor (Hechavarrıa et al., 2017).

\section{METODOLOGIA}

A metodologia utilizada foi do tipo exploratória (Creswell, 2010; Martins \& Teóphilo, 2009), por se tratar de um tema relativamente novo, com pouco conhecimento acumulado e sistematizado dentro do Empreendedorismo Social (Acs et al., 2013; Albert et al., 2016; Chell et a.l, 2016; Hechavarría et al., 2017; Hlady-Rispal \& Servantie, 2018; Kraus \& Filser, 2014; Mair, Battilana \& Cardenas., 2012; Medeiros, Machado, Pereira, Costa \& Gomez 2017). A opção metodológica foi a indução analítica, que tem como "prioridade temporal da observação não estruturada dos feitos não estruturados com a finalidade de gerar conceitos e teorias" (Penalva, Alaminos, Francés, \& Santacreu, 2015, p. 27).

A abordagem para a pesquisa foi do tipo qualitativa (Flick, 2012; Di Domenico, Haugh \& Tracey, 2010; Stake, 2011; Sassmannshausen \& Volkmann, 2013). 
No que se refere ao método de pesquisa proposto, optou-se por estudo de caso único, numa associação brasileira do terceiro setor, Rede IVG (Creswell, 2010; Neiman \& Quaranta, 2014; Stake, 2011; Yin, 2016; Di Domenico et al., 2010). No que se refere as técnicas de coleta de dados e evidências, foram utilizadas entrevistas semiestruturadas em profundidade (Penalva et al., 2015; Stake, 2011), análise de documentos (Martins \& Teóphilo, 2009; Penalva et al., 2015), e observação não participante (Penalva et al., 2015; Poupart, 2008). As técnicas de análise foram orientadas para a construção conceitual a partir de dados não estruturados, proveniente das técnicas de entrevista em profundidade, entrevista em grupo, análise documental e observação não participante, (Flick, 2012, Penalva et al., 2015). A análise das informações qualitativas foi realizada com base na análise do discurso e com apoio do software Atlas TI para definição dos valores sob a ótica dos sujeitos. Foram entrevistados 21 sujeitos, que participam de forma direta ou indireta do empreendimento brasileiro, com variáveis sociodemográficas distintas, importantes e necessárias e que pudessem garantir diferentes discursos sobre o objeto da pesquisa (Martins \& Teóphilo, 2009; Creswell, 2010; Penalva et al., 2015), e estabeleceram-se como critérios: serem maiores de 18 anos, responsável por seus atos e falas, com formação educacional formal reconhecida pelos órgãos competentes no país, participante ou egresso do empreendimento, ter sido beneficiado de forma direta ou indireta, ou ter participado em algum momento da trajetória do empreendimento social (Penalva et al., 2015; Stake, 2011).

Para a análise das informações qualitativas, foram utilizados métodos que permitissem de forma simultânea a análise descritiva a análise geradora de teoria e a análise baseada nos discursos dos sujeitos. Na análise descritiva ocorre uma primeira exploração dos materiais textuais com o objetivo de analisar os temas de que falam os entrevistados, análise das atitudes a respeito de valores em forma de crenças, sentimentos, comportamentos, as suas motivações intrínsecas e extrínsecas, as designações dos objetos pesquisados e as relações com os sujeitos que podem ter dualidade como funcional $x$ utilitárias, ou ainda os processos e oposições em relação a outros fatos ou objetos pesquisados (Penalva et al., 2015). E na classificação das informações qualitativas, que visam a sua interpretação e a explicação por meio da produção de um informe adequado e significativo do que se quer entender na pesquisa. Este é um momento de montagem de um 'quebra-cabeças', buscando identificar as diversas facetas da vida social e suas múltiplas conexões. 
Deve-se levar em conta que o pano de fundo é a realidade social pesquisada, onde foram gerados os dados, sendo que cada frase, observação, nota de campo, sequências de informações ou outro dado relevante, são partes deste trabalho de montagem (Dey, 1993; Penalva et al., 2015).

Para a análise geradora de teoria foi utilizada a Grounded Theory (GT) também chamada de Teoria Fundamentada (TF), proposto por Glaser e Strauss (1967) no livro The discovery of grounded theory: strategies for qualitative research, onde o objetivo maior é dar preferência aos dados do campo, ao invés dos pressupostos teóricos, com a intenção de que a pesquisadora não perca sua atenção, com a canalização para os resultados. Este método tem por característica a indução analítica, pois se busca a aproximação do tema de pesquisa, sem uma teoria de base, ou a teoria ainda se encontra em construção no campo teórico, permitindo a formulação de uma teoria com fundamentos empíricos e novas visões de um fenômeno (Hernandéz et al., 2006; Penalva et al., 2015). A GT, por natureza é uma metodologia que se aproxima do assunto a ser investigado sem uma teoria a ser testada. Os elementos analíticos da GT podem ser descritos como: a amostra e saturação teórica; incidente, código, categoria e a categoria central (Penalva et al, 2015, p. 89-90). Este processo tem como objetivo a redução de dados, para que o pesquisador possa analisar as informações qualitativas de modo a dar um novo sentido ao que foi falado, bem como resignificar dentro do contexto de estudo (Penalva, 2003). Para a construção da teoria, Charmaz (2009, p. 173) afirma que há a necessidade da "compreensão imaginativa do fenômeno estudado", levando em consideração ainda pressupostos de "realidades múltiplas e emergentes, indeterminação, fatos e valores quando associados, a verdade como algo provisório e a vida social como um processo." Para a construção teórica da GT, o pesquisador necessita de elementos básicos como: as categorias, suas propriedades e as proposições de pesquisa, tendo como uma de suas características fundamentais a linha de ação investigativa invertida, movendo-se da observação empírica para a definição de conceitos. Esta teoria propõe que a articulação dos componentes de forma constante, visando à maximização das similaridades e minimização das diferenças, permitindo assim a delimitação teórica. Para a operacionalização, torna-se necessário que ocorra inicialmente um processo de redução das categorias, que seja possível a determinação de uma categoria central, conectando-se assim esta categoria a outras, fazendo-se a conexão entre elas (Penalva et al., 2015; Soneira, 2014). Na GT, a teoria substantiva é importante na interação sistemática e constante das categorias. No desenvolvimento do presente trabalho 
optou-se pela GT, pois permite que os dados sejam obtidos por meio e com origem no campo, o que contribui para o campo de pesquisa emergente, que é o empreendedorismo social.

Para a análise dos dados e informações qualitativas optou-se pela Análise do Discurso (AD), que é uma metodologia que tem por objetivo, não somente verificar como a mensagem é transmitida, mas também qual é o seu sentido. É por meio da linguagem que o discurso é possível, e o processo comunicativo entre o pesquisador e seu sujeito, é a fonte utilizada pelo pesquisador para obter informações que são consideradas importantes, principalmente para atender aos objetivos da pesquisa (Alonso, 2003; Orlandi, 2015). Pode ser definida como um conjunto de métodos e procedimentos baseados em semiótica e estruturalismo. Caracteriza-se por uma variedade de tradições e práticas, de caráter interdisciplinar, que visa à interpretação da ação social dos sujeitos num determinado contexto, seja ele, social, econômico, político e cultural (Alonso, 2003; Pêcheux, 2006; Penalva et al., 2015). O discurso tem como finalidade por meio da linguagem a busca de leis gerais de validade praticamente universal, mas que tenha sentido para os sujeitos envolvidos, envolvendo além da linguagem, a comunicação não verbal do sujeito (Orlandi, 2015), e como afirma Alonso (2003), o discurso transborda o texto. A AD tem como característica a utilização da linguagem como ponto de partida para a definição dos demais materiais de análise, de modo a ter instrumentos que vão além de promover intercâmbios significativos. E por fim, a $A D$ na área de Ciências Sociais pode produzir discursos não desejados, como por exemplo, discurso de censura (Penalva et al., 2015).

Para a AD, a análise deve orientar-se de forma que possa articular-se entre os significados próprios de uma sociedade ou determinado grupo, sobre um tema específico de maneira que possa expressar significados e fazer efetivas as suas intenções por meio dos discursos, "investido de significância para e por sujeitos" (Orlandi, 2015, p. 24; Penalva et al., 2015). Sob a ótica do analista, Orlandi $(2015$, p. 58) salienta que o ato de escutar do discurso já é uma interpretação, pois "uma mesma palavra, na mesma língua, significa diferentemente, dependendo da posição do sujeito e da inscrição do que diz em uma ou outra formação discursiva." A autora ainda argumenta que a interpretação ocorre em dois momentos: primeiro quando se considera a própria interpretação já como parte do objeto de análise, e em segundo lugar, quando o próprio analista está envolvido no processo de interpretação, necessitando, pois, o analista deslocar-se desta relação sujeito/interpretação. 
Ainda na análise das informações qualitativas, optou-se por fazer etapas de análise com a função de reduzir os dados obtidos, e configurá-los de forma que tenham significado, e ocorrem processos simultâneos de seleção, simplificação, abstração, focalização e transformação dos dados oriundos a partir da etapa de coleta de dados. Nesta fase de análise, o uso do software ATLAS TI contribuiu para a organização dos dados e informações de forma a "gerenciar, extrair, explorar e reestruturar os elementos significativos dos dados" (Penalva et al., 2015, p. 127), reconfigurando-se de maneira a construir as teorias a que se referem os dados e fenômenos estudados. Com o auxílio do software foi possível entender as propriedades dos dados por meio da sua visualização, integração entre os entre as diversas categorias emergentes criando a Unidade Hermenêutica (códigos, anotações, memórias e citações), serendipidade que visa as descobertas mesmo que por acaso, e pôr fim a exploração, que o programa contribui para estabelecer as conexões e descobrimento das relações para a construção da teoria (Penalva, 2003).

\section{ANÁLISE DOS DADOS E EVIDÊNCIAS DA PESQUISA DE CAMPO}

Uma das organizações sociais objeto de estudo foi a Rede IVG, que por meio de suas ações tem por objetivo a inclusão de pessoas que estão à margem ou excluídas da sociedade brasileira, por meio de inclusão por meio da educação e resgate de direitos básicos assegurados pela legislação na região da Grande Florianópolis, sul do Brasil.

No processo de criação de valor junto aos beneficiários, comunidades, voluntários, gestores públicos e privados, pode-se verificar que o processo de criação de valor ocorre pela efetiva inclusão de moradores de periferia em espaços sociais que são garantidos pelas políticas públicas e assegurados constitucionalmente.

Os valores explicitados sob a ótica dos participantes da Rede IVG, mostram como ocorre à interação entre os diversos stakeholders, por meio de reconhecimento dos valores, e as transformações que ocorrem nas vidas destes participantes.

A criação de valor social promovida pela Rede IVG pode ser visualizada na Rede de Valores no processo de Criação de Valor, como mostra a Figura 1. 


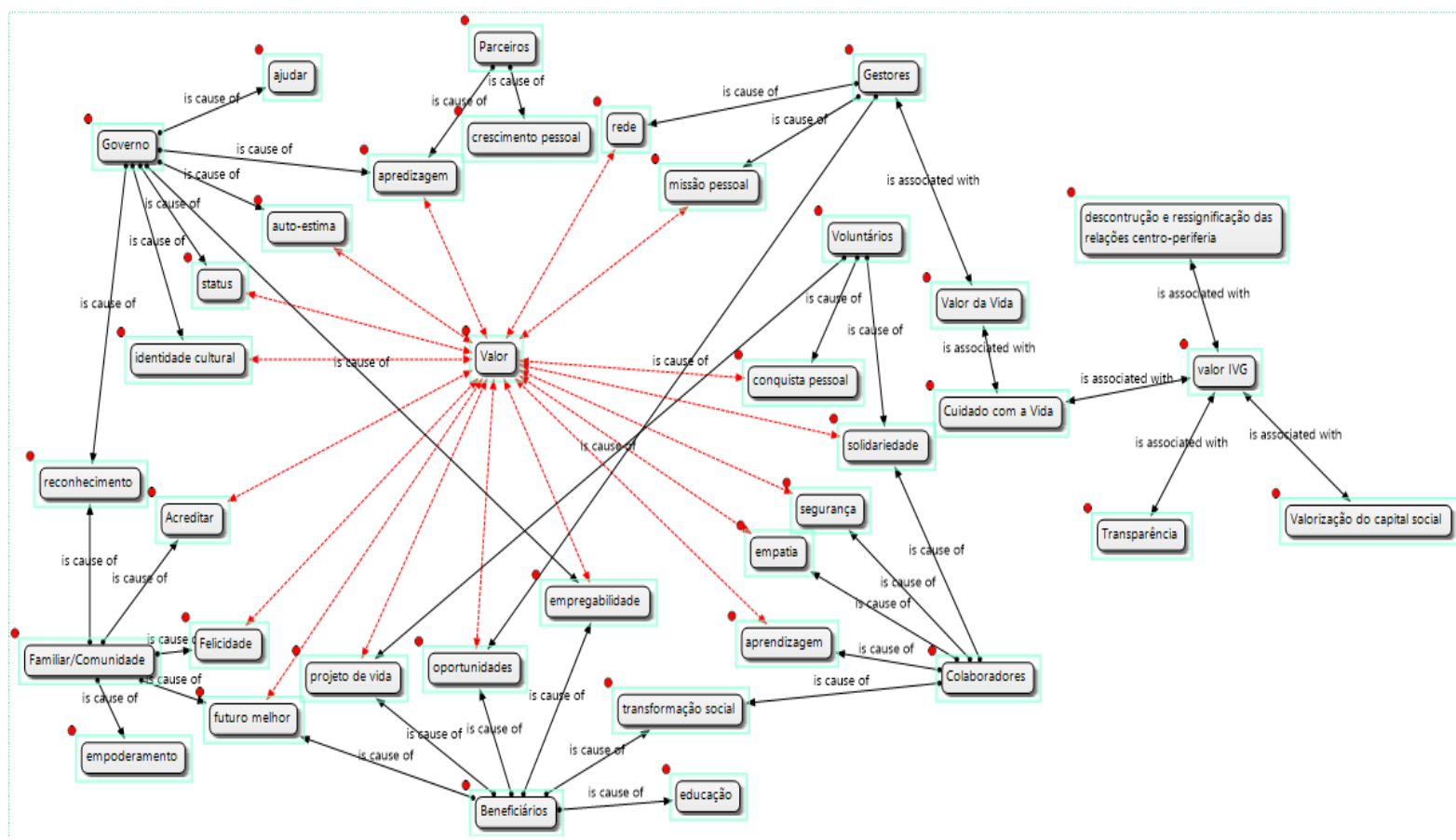

Figura 1 - Rede de Valores da Rede IVG com apoio do software Atlas TI

Fonte: Pesquisa de Campo (2017).

A Rede IVG, apresenta na sua estrutura seus princípios e valores organizacionais que norteiam as atividades e ações de toda a Rede, tendo como objetivo principal a "encontrar respostas criativas para os problemas da população [...] na construção de um futuro melhor para as pessoas destituídas de direitos (Rede IVG, 2017). Pode-se verificar ainda, que de um lado, os valores organizacionais têm o cuidado com a vida, de forma que permitam às populações vulneráveis de forma a inclui-los na vida das cidades, na busca permanente da desconstrução e ressignificação das relações entre centro e periferia, transformando a exclusão em inclusão por meio da sua missão, visão, princípios e valores, criando valor para estas comunidades e seus moradores.

O diferencial que a Rede IVG promove na vida das populações vulneráveis por meio da educação visa promover a inclusão nos diversos espaços sociais de forma a desenvolver e integrar as comunidades de periferia na vida da cidade. Os valores elencados pelos sujeitos da pesquisa, com base na Teoria de Valores de Schwartz (1992), e no locus de valor nos sujeitos pesquisados, ou seja, sob a ótica de individuo, são explicitados na Figura 1.

Dentre os valores encontrados na pesquisa de campo na Rede IVG, pode-se destacar primeiramente os valores ligados à conservação, pois as pessoas estão mais preocupadas 
em sair de condições de vulnerabilidade em que se encontram, buscam a segurança que ainda não possuem e que almejam. Corroborando com a perspectiva materialista também é explicitada pela visão de mundo e na criação de valor gerado pela rede IVG, sob a ótica dos multistakeholders, reforçando os valores de conservação e autoproteção definidos por Schwartz (2012). Assim, a combinação das duas teorias por ser comprovada na perspectiva materialista dos sujeitos pesquisados na Rede IVG, como mostra a Figura. 2.

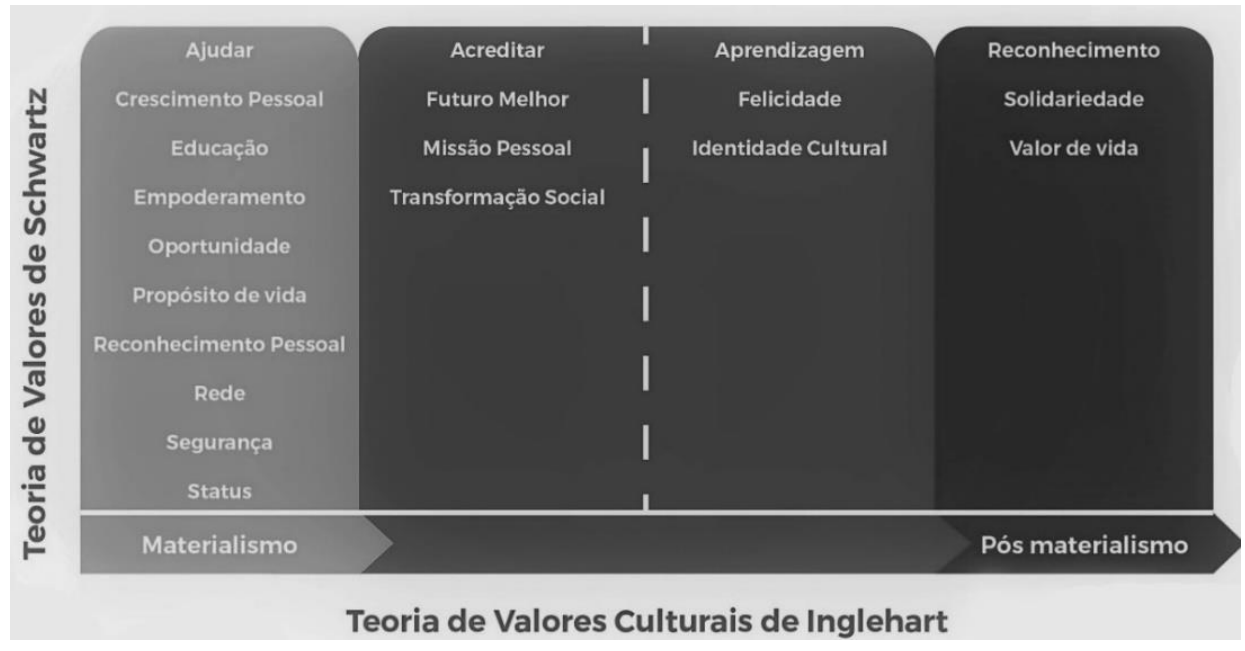

Figura 2 - Criação de Valor sob a ótica dos Sujeitos.

Fonte: Dados da Pesquisa (2017).

Os valores destacados a partir da análise dos seus discursos foram: crescimento pessoal por meio da educação, que se tornou um valor, empoderamento, identidade cultural, oportunidade aliada ao propósito de vida, reconhecimento pessoal associado ao status adquirido com a nova condição social, o que gera valores associados à perspectiva social como: a felicidade, futuro melhor, a possibilidade de poder ajudar contribuindo para que as outras pessoas da comunidade tenham as mesmas oportunidades, a segurança propriamente dita, bem como, a rede gerada pelos envolvidos contribui para a transformação social. A seguir os valores ligados a autotranscedência como: aprendizagem proporcionada pelas ações da Rede, empatia de colocar-se no lugar do outro, missão pessoal e solidariedade em contribuir para uma vida melhor, e por fim o valor da vida, o bem maior que uma pessoa pode ter independente da sua condição social, econômica, política ou cultural. E por último o reconhecimento de um trabalho pela sociedade que está inserida, além da identidade cultural proporcionada a estas pessoas, o valor de pertencer a um lugar que é seu por direito. 
Na teoria de Inglehart $(1977,2009)$, a mudança de valores numa sociedade acontece de forma lenta e gradual, sendo a escassez e a socialização são dois pontos cruciais para a mudança de valores, tanto nos indivíduos como nas sociedades. A realidade brasileira tem se mostrado ao longo dos anos dentro a perspectiva de escassez principalmente de recursos materiais para o atendimento das necessidades básicas como educação, saúde e segurança. Os indivíduos buscam assim superar situações ligadas a violência, devido à sensação de insegurança provocada pelos constrangimentos em relação a si e aos seus. Neste sentido, há uma tendência de privilegiar o desenvolvimento material e objetivo como forma de se obter meios de proteção, seja ela pessoal ou patrimonial, ou seja, os valores priorizados pelos indivíduos está ligado diretamente ao meio em que vive, sendo ele um dos principais fatores influenciadores destes valores (Inglehart 1997, 2009; Ribeiro, 2007).

Fazendo uma correlação com a teoria de Inglehart (2009), os valores apresentados pelos sujeitos são considerados materialista, pois ainda buscam colocação nos espaços sociais, sendo muitas vezes marginalizados e/ou excluídos, necessitando de movimentos reivindicatórios para assegurar o acesso a direitos básicos e nem sempre disponibilizados, bem como as políticas públicas deficitárias e um Estado que não promove a garantia de direitos básicos à sociedade. No que se refere a validação dos resultados e para apoiar a análise, optou-se pela análise vertical e horizontal das informações qualitativas. $\mathrm{Na}$ análise vertical, se analisou o empreendimento de acordo com os discursos dos sujeitos da pesquisa, por meio da sua participação da trajetória na organização social, por meio das narrativas dos discursos e suas interfaces para a compreensão do caso de maneira conjunta e integrada como resultado da pesquisa. $\mathrm{Na}$ análise horizontal, buscou-se verificar as dimensões estudadas em função da combinação entre os resultados do estudo de caso, bem como as consistências dos parâmetros utilizados, com foco no valor social desenvolvido no empreendimento estudado (Amber-Montes, 2016).

\section{CONCLUSÃO}

Este artigo tem por objetivo identificar os valores sob a ótica dos sujeitos na Rede IVG, tendo como base a Teoria de Valores de Schwartz (2012) e a Teoria de Valores Culturais de Inglehart (1977, 1990, 1997), a partir da análise dos seus discursos. A Rede IVG, dentro de seus documentos norteadores, tem como objetivo principal a "encontrar respostas criativas para os problemas da população [...] na construção de um futuro melhor para as pessoas destituídas de direitos (Rede IVG, 2017). Seus valores os valores organizacionais têm o 
cuidado com a vida, de forma que permitam às populações vulneráveis de forma a inclui-los na vida das cidades, na busca permanente da desconstrução e ressignificação das relações entre centro e periferia, transformando a exclusão em inclusão por meio da sua missão, visão, princípios e valores, criando valor para estas comunidades e seus moradores. Já os valores encontrados na pesquisa de campo na Rede IVG, pode-se destacar primeiramente os valores ligados à conservação, pois as pessoas estão mais preocupadas em sair de condições de vulnerabilidade em que se encontram, buscam a segurança que ainda não possuem e que almejam.

Os valores destacados pelos sujeitos sob a perspectiva pessoal foram: crescimento pessoal por meio da educação, que se tornou um valor, empoderamento, identidade cultural, oportunidade aliada ao propósito de vida, reconhecimento pessoal associado ao status adquirido com a nova condição social, o que gera valores associados à perspectiva social como: a felicidade, futuro melhor, a possibilidade de poder ajudar contribuindo para que as outras pessoas da comunidade tenham as mesmas oportunidades, a segurança propriamente dita, bem como, a rede gerada pelos envolvidos contribui para a transformação social.

Os valores ligados a autotranscedência como: aprendizagem proporcionada pelas ações da Rede, empatia de colocar-se no lugar do outro, missão pessoal e solidariedade em contribuir para uma vida melhor, e por fim o valor da vida, o bem maior que uma pessoa pode ter independente da sua condição social, econômica, política ou cultural. E por último o reconhecimento de um trabalho pela sociedade que está inserida, além da identidade cultural proporcionada a estas pessoas, o valor de pertencer a um lugar que é seu por direito.

A partir da presente pesquisa pode-se verificar que a inclusão por meio da educação é possível romper o ciclo de pobreza e a possibilidade de seguir caminhos diferentes ao comumente oferecidos a estas comunidades como serviços braçais ou com pouca especialidade, para atividades de cunho intelectual, ou em outros espaços de mercado de trabalho que requerem maior nível de escolaridade. Por meio dos discursos dos sujeitos pode-se verificar ainda por meio da integração de diversos atores é possível promover a inclusão. 
Para Inglehart (2009) e Ribeiro (2007), as condições socioeconômicas dos indivíduos afetam seus valores, pois a sobrevivência é fator determinante influenciados diretamente pelos fatores sociais, econômicos e políticos. Eles ainda argumentam que programas de redução da pobreza e elevação dos níveis educacionais já contribuiriam para uma mudança nas habilidades cognitivas dos indivíduos, levando-os à independência intelectual e por consequência sua autonomia. Para o desenvolvimento de uma sociedade, é imprescindível a inclusão de todos nos espaços sociais, garantindo-Ihes direitos e deveres para o pleno desenvolvimento da cidadania.

O Brasil, ainda tem muito o que avançar para ser uma sociedade que inclui plenamente seus cidadãos. Ainda faltam mecanismos que assegurem, desde estabilidade social, política econômica, geração de emprego e renda principalmente nos níveis mais baixos da população, a melhoria na distribuição de renda, além de garantia de acesso aos serviços de saúde, educação e segurança, considerados básicos, para podermos assim ser considerados uma sociedade mais justa e inclusiva.

No que se refere a trabalhos futuros, sugere-se estudar: a sucessão em empreendimentos sociais, os fatores internos e internos que interferem no desenvolvimento das atividades em empreendedorismo social, os valores inerentes aos empreendimentos sociais sob diferente óticas, contextos, segmentos e objetivos, o papel do líder como motivador na criação de empreendimentos sociais, analisar sob a ótica financeira e de sustentabilidade dos empreendimentos sociais.

Quanto as limitações do presente estudo, destacam-se os poucos estudos empíricos em ES, que muitas vezes se limitam a definição de ES, papel do empreendedor social e missão social, necessitando assim de mais estudos sobre fatores que interferem neste campo de estudo, possibilidade de avanços nos estudos desta área.

Além disso, a área de ES no Brasil ainda está em fase de consolidação, principalmente pela recente demarcação por meio de leis e decretos.

A academia ainda não despertou para este tema de tamanha relevância e que pode contribuir para a resolução de problemas sociais e econômicos. 


\section{REFERÊNCIAS}

Acs, Z. J., Boardman, M. C., \& McNeely, C. L. (2013). The social value of productive entrepreneurship. Small Bus Econ, 40, 785-796.

Agostini, M. R. (2016). Correlações entre diferentes terminologias no contexto do terceiro setor: Inovação social $x$ empreendedorismo social x Empresa social x Negócio social. Anais do Congresso Brasileiro de Estudos Organizacionais, Porto Alegre, RS, Brasil, 4.

Albert, L. S., Dean, T. J., \& Baron, R. A. (2016). From Social Value to Social Cognition: How Social Ventures Obtain the Resources They Need for Social Transformation. Journal of Social Entrepreneurship, 289-311.

Amber-Montes, D. (2016). Mayores de 45 años en desempleo. Historias silenciadas y desafíos e la formación. Tesis Doctorales, Universidad de Granada, Espanha.

Alvord, S. H. L., Brown, D., \& Letts, C. W. (2004, September). Social Entrepreneurship and Societal Transformation: An Exploratory Study. The Journal of Applied Behavioral Science, 40, 260-282.

Austin, J, Stevenson, H., \& Wei-Skillern, J. (2006). Social and Commercial Entrepreneurship: Same, Different, orBoth?. Entrepreneurship Theory and Practice, 30(1), 1-22.

Bacq, S., \& Janssen, F. (2011, June). The multiple faces of social entrepreneurship: A review of definitional issues based on geographical and thematic criteria. Entrepreneurship \& Regional Development, 23(5-6), 373-403.

Bernardino, S. J. Q. (2013). Iniciativas de empreendedorismo social no Terceiro Setor em Portugal: antecedentes, comportamentos e desempenho organizacionais. Tese de Doutoramento, Universidade Portucalense,

Portugal. Recuperado em 20 de janeiro, 2018, de

http://repositorio.uportu.pt/jspui/handle/11328/1045

Chaves Ávila, R., Monzón Campos, J. L., Pérez De Uralde, J. M., \& Radrigán, M. (2013). La Economía Social En Clave Internacional. Cuantificación, Reconocimiento Institucional Y Visibilidad Social En Europa, Iberoamérica Y Norte De África. REVESCO. Revista de Estudios Cooperativos, 112, 122-150.

Chell, E. (2007). Social Enterprise and Entrepreneurship. Towards a convergent theory of the entrepreneurial process. International Small Business Journal, 25(1), 5-26.

Chell, E., Spence, L. J., Perrini, F., \& Harris, J. D. (2016). Social Entrepreneurship and Business Ethics: Does Social Equal Ethical? J Bus Ethics, 133, 619-625.

Creswell, J. W. (2010). Projeto de Pesquisa: método qualitativo, quantitativo e misto. Porto Alegre: Artmed.

Di Domenico, M. L., Haugh, H., \& Tracey, P. (2010, July). Social Bricolage: Theorizing Social Value Creation in Social Enterprises. Entrepreneurship, Theory and Practice, 34(4), 681-703.

Flick, U. (2012). Introducción a la investigación cualitativa (3a ed.). Madrid/Es: Ed. Paideia.

Hlady-Rispal, M., \& Servantie, V. (2018). Deconstructing theWay in which Value Is Created in the Context of Social Entrepreneurship. International Journal of Management Reviews, 20, 62-80. 
Inglehart, R. (1977). The silent revolution. Princeton, NJ: Princeton University. . (1990). El cambio cultural en las sociedades industriales avanzadas. Madrid, España: Siglo XXI.

. (1997). Modernization and Postmodernization: cultural, economic and political change in 43 societies. New Jersey/USA: Princeton University Press.

Inglehart, R., \& Díez Nicolas, J. (2005). Tendencias Mundiales de cambio em los valores sociales e políticos. Madri, ES: Los libros de Fundesco.

Inglehart, R. \& Welzel, C. (2005). Modernization, cultural change, and democracy: the human development sequence. New York: Cambridge University Press.

Kraus, S., Filser, M., O'Dwyer, M., \& Shaw, E. (2014). Social entrepreneurship: an exploratory citation analysis. Review of Managerial Science, 8, 275-292.

Kostetska, I., \& Berezyak, I. (2014). Social entrepreunership as in innovative solution machanism of social problems of society. Manangement Theorya adn Studies for Rural Business and Infrastructure Development, 36(3).

Lautermann, C. (2013). The ambiguities of (social) value creation: towards an extended understanding of entrepreneurial value creation for society. Social Enterprise Journal, 9(2), 184-202.

Mair, J.; Marti, I. (2006). Social entrepreneurship research: A source of explanation, prediction, and delight. Journal of World Business, 41(1), 36-44.

Mair, J., Battilana, J., \& Cardenas, J. (2012). Organizing for society: a typology of social entrepreneuring models. Journal of Business Ethics, 111, 353-373.

Martinez, F., O'Sullivan, P., Smith, M., \& Esposito, M. (2017). Perspectives on the role of business in social innovation. Journal of Management Development, 36(5), 681-695.

Martins, G. D. A., \& Theófilo, C. R. (2009). Metodologia da Investigação Científica para Ciências Sociais (2a ed.). São Paulo/SP: Editora Atlas.

Maslow, A. H. (1954). Motivation and personality. New York, Harper.

Medeiros, C. B., Machado, L. C. R., Pereira, L. C.de A., Costa, Í. C. de A., \& Gomez, C. P. (2017). Inovação Social e Empreendedorismo Social: Uma Análise Sob a Perspectiva da Economia Solidária. Revista Gestão.Org, 15(1), 61-72.

Murphy, P. J., \& Coombes, S. M. (2009, July). A Model of Social Entrepreneurial Discovery. Journal of Business Ethics, 87(3), 325-336.

Neiman, G., \& Quaranta, G. (2014). Los estúdios de caso em la investigación sociológica. In I. V. Gialdino (Coord.). Estrategias de investigación cualitativa (Cap. 6, pp. 213-234). Barcelona, ES: Ed Gedisa.

Nicholls, A. (2006). Social Entrepreneurship: New paradigms of sustainable social change. Oxford University Press, Oxford: OCDE.

Omorede, A. (2014). Exploration of motivational drivers towards social entrepreneurship. Social Enterprise Journal, 10(3), 239-26. 
Parente, C., Costa, D., Santos, M., \& Chaves, R. R. (2011, Maio). Empreendedorismo social: contributos teóricos para a sua definição. Anais do Encontro Nacional de Sociologia Industrial, das Organizações e do Trabalho Emprego e coesão social: da crise de regulação à hegemonia da globalização Lisboa, Lisboa, 14.

Penalva, C. V., Alaminos, A. C, Francés, F. J. G., \& Santacreu, O. A. F. (2015). La investigación cualitativa: Técnicas de Investigación y Análisis con Atlas.Ti., Universidad de Cuenca/Cuenca, Equador: PYDLOS Ediciones.

Peredo, A. M., \& McLean, M. (2006). Towards a theory of community-based enterprise. Academy of management Review, 31(2), 56-65.

Poupart, J. et al. (2008). A pesquisa qualitativa: enfoques epistemológicos e metodológicos. Petrópolis/RJ: Vozes.

Rede IVG. (2017). Recuperado em 28 de outubro 2017, de http://www.redeivg.org.br/

Ribeiro, E., Borba, J. (2010, Junho). Participação e pós-materialismo na América Latina. Revista Opinião Pública, Campinas, 16(1), 28-63.

Sassmannshausen, S. P., \& Volkmann, C. (2013). A bilbiometric based rewiev on Social Entrepreunership and its establishment as a Field of Research. Schumpeter Discussion Paper, (3).

Schwartz, S. H. (1992). Universals in the context and structure of values: theoretical advances and empirical tests in 20 countries. In M. Zanna (Org.). Advances in experimental social psychology (vol. 25, pp. 1-65). Orlando: Academic Press.

Schwartz, S. H. (2005). Robustness and fruitfulness of a theory of universals in individual human values. In A. Tamayo, \& J. B. Porto (Eds.). Valores e comportamento nas organizações [Values and behavior in organizations] (pp. 56-95). Petrópolis, Brazil: Vozes.

Schwartz, S. H. (2012). An Overview of the Schwartz Theory of Basic Values. Online Readings in Psychology and Culture, 2(1).

Schwartz, S. H., Cieciuch, J., Vecchione, M., Davidov, E., Fischer, R., \& Konty, M. (2012). Refining the theory of basic individual values. Journal of Personality and Social Psychology, 103, 663-688.

Stake, R. (2011). Pesquisa qualitativa: estudando como as coisas funcionam. Porto Alegre/RS: Penso.

World Values Survey Association. (2017). Aggregate File Producer. Madrid, Spain: Asep/JDS. Recuperado em 15 de janeiro, 2018, de www.worldvaluessurvey.org

Yin, R. K. (2016). Pesquisa qualitativa do início ao fim. Porto Alegre: Penso. 